\title{
FAKTOR PENYEBAB PERMUKIMAN KUMUH DI KELURAHAN BAGAN DELI BELAWAN KOTA MEDAN
}

\author{
Kaspan Eka Putra ${ }^{1}$, Melly Andriana ${ }^{2}$ \\ Teknik Arsitektur Fakultas Teknik Universitas Pembangunan Panca Budi \\ Jl. Gatot Subroto No.km, Simpang Tj., Kota Medan \\ *Email: ${ }^{1}$ kaspan12.kp@gmail.com, ${ }^{2}$ melly.andriana69@gmail.com
}

\begin{abstract}
Settlement Region and Urban slum is a big problem that must be solved in the Development Process. In Medan, there are some urban slums, one of these slum areas is in Bagan Deli, Lingkungan Lorong Mesjid Village, Medan Belawan. This study aims to determine the factors that caused untidiness in this slum area. Methods of the study was conducted with direct observation on the region. The data that already obtained are used as basis of analysis for answering the problems of the study, namely to know the factors that caused untidiness in this slum area. From the results of research findings that there are 5 factors that cause untidiness, that are population density factor, income factor, land ownership factor, occupant behavior factor, and care services factors include the availability of facilities and infrastructure. After knowing the factors of untidiness in slum area, then will make the best solutions, that is revitalization (rebuilding) operating physical and socioeconomic.
\end{abstract}

Keywords: Slum area and factors.

\section{PENDAHULUAN}

Kota Belawan merupakan pintu gerbang Kota Medan dari jalur transportasi laut. Status Pelabuhan Belawan merupakan pelabuhan internasional dengan intensitas yang sangat tinggi menempatkan kawasan ini menjadi salah satu pusat pertumbuhan kawasan strategis nasional. Namum dibalik tingkat perkembangan ekonomi kawasan yang sangat tinggi, terdapat permasalahan kemiskinan yang juga tertinggi dibandingkan dengan kawasan Kota Medan lainnya.

Status Pelabuhan Belawan merupakan pelabuhan internasional dan menjadi salah satu kawasan strategis nasional tampaknya tidak sejalan dengan kondisi perekonomian warganya terutama di kawasan Kelurahan Bagan Deli, yang mayoritas bermata pencaharian sebagai nelayan/penangkap kerang. Di samping itu, juga telah terjadi pencemaran pantai yang bersumber dari limbah industri/pabrik di hulu dan sampah rumah tangga. Sampah masih merupakan masalah karena telah mencemari sungai dan lokasi tempat tinggal masyarakat. Hal ini dikarenakan masih banyaknya anggota masyarakat yang membuang sampah ke sungai.

Akibat masalah pencemaran ini, di kawasan Bagan Deli juga dijumpai masalah yang berhubungan dengan adanya bangunan kumuh. Rumah-rumah penduduk dibangun dengan semi permanen dengan ukuran relatif kecil dan terbuat dari papan dan tepas. Rumah tersebut dibangun seadanya di atas paluh yang jika air laut surut daratannya terlihat sangat kotor karena sampah dan kotoran manusia yang berserakan sehingga membuat perumahan/lingkungan ini menjadi sangat kumuh. Sangat banyak masalah kesehatan yang ada di lingkungan kumuh ini, diantaranya penyakit ISPA, penyakit kulit serta rendahnya pemenuhan kebutuhan pokok yang mencakup masalah gizi yang belum lengkap.

Berdasarkan kondisi di atas, penelitian ini akan mengungkapkan faktor-faktor apa saja yang menyebabkan kekumuhan di Kelurahan Bagan Deli agar dapat menjawab permasalahan dan membuat solusi dalam bentuk perencanaan penataan permukiman kumuh dan lingkungan. 


\section{METODE PENELITIAN}

Permukiman kumuh adalah permukiman yang tidak layak huni karena ketidakteraturan bangunan, tingkat kepadatan bangunan yang tinggi, dan kualitas bangunan serta sarana dan prasarana yang tidak memenuhi syarat (UU No.1 Tahun 2011). Dengan alasan ingin memiliki perubahan pendapatan dan kondisi hidup yang lebih baik, penduduk melakukan perpindahan atau migrasi (Iman, 2014); (Bolay, 2006). Perpindahan ini menimbulkan kepadatan penduduk (Marx, et al, 2013) yang berujung pada terciptanya lingkungan yang tidak sehat (Goswani dan Samita, 2013). Kurangnya fasilitas ekonomi dan sumber daya juga memicu kemiskinan di wilayah kumuh (Bagheri, 2012). Lingkungan yang kumuh dapat merusak kesehatan (Pryer, 2006).

Pertumbuhan ekonomi yang pesat turut menimbulkan permukiman kumuh (Roy et al, 2014). Suatu kawasan tidak sanggup mengikuti alur pertumbuhan ekonomi tersebut. Kondisi sosial ekonomi penghuni (Çiçeklioğlu et al, 2012) yang juga mencakup kondisi pendidikan juga menjadi pemicu kemiskinan (Ucha, 2010) dan pendapatan penghuninya (Sakdapolrak, 2013). Guna merencanakan penataan permukiman kumuh, maka harus diketahui fenomena dan penyebab (Bolay, J.C.,2006), infrastruktur (Desai, 2012), pola kepemilikan rumah (Gulyani, et.al, 2012), akses terhadap air bersih (Dagdeviren, 2011), keadaan fasilitas limbah pembuangan (Bandyopadhyay dan Vandana, 2013), pelayanan (Idowu, 2013) turut menjadi pemicu terjadinya permukiman kumuh disuatu kawasan.

Penelitian ini dilaksanakan di Kelurahan Bagan Deli Kecamatan Medan Belawan dengan fokus pada 11 gang yang terdapat di Lingkungan Lorong Mesjid. Penelitian ini menggunakan metode pendekatan deskrtiptifkualitatif yang didasarkan atas penelitian yang bersifat eksploratif rasionalistik dengan menggali informasi dari masyarakat tanpa menentukan batas variabel maupun indikator yang secara partisipatif bertujuan deskriptif yaitu menggambarkan situasi yang ada dan nantinya mengambil kesimpulan dari hasil yang diperoleh.

Data primer diperoleh dari hasil survey lapangan (observasi) melalui cara pengamatan langsung di lokasi penelitian. Wawancara untuk mengumpulkan data secara langsung, dokumentasi dengan cara merekam potret objek terkait dan aktivitas di kawasan permukiman Lorong Mesjid. Untuk mendapatkan faktorfaktor penyebab kekumuhan di kawasan permukiman Lorong Mesjid menggunakan metode analisis deskriptif sebagai gambaran terstruktur dalam identifikasi kawasan permukiman kumuh ini dengan menganalisis persepsi penghuni dalam kaitannya dengan penyebab kekumuhan lingkungan kawasan permukiman.

Dalam tahap analisis ini, identifikasi dan analisis yang dilakukan bertujuan untuk dapat mengetahui bagaimana persepsi penghuni terhadap penyebab kekumuhan lingkungan kawasan permukiman tempat mereka tinggal. Aspek-aspek yang digali terhadap persepsi penghuni ini berupa aspek sosial dan fisik, diantaranya faktor kepadatan permukiman, kepemilikan lahan, tingkat penghasilan, kepadatan jumlah penduduk yang tinggal, karakteristik bangunan, serta ketersediaan sarana dan prasarana dasar yang mendukung.

\section{HASIL DAN PEMBAHASAN}

Permukiman kumuh merupakan salah satu masalah perkotaan yang timbul akibat dari tidak mempunyai sebuah kawasan mengikuti alur pertumbuhan ekonomi yang ada sehingga menimbulkan kemiskinan yang berdampak pada lingkungan sosial maupun lingkungan fisik kawasan tersebut.

Lokasi kawasan kumuh Kelurahan Bagan Deli, tepatnya pada kawasan Lorong Mesjid (Gambar 1).

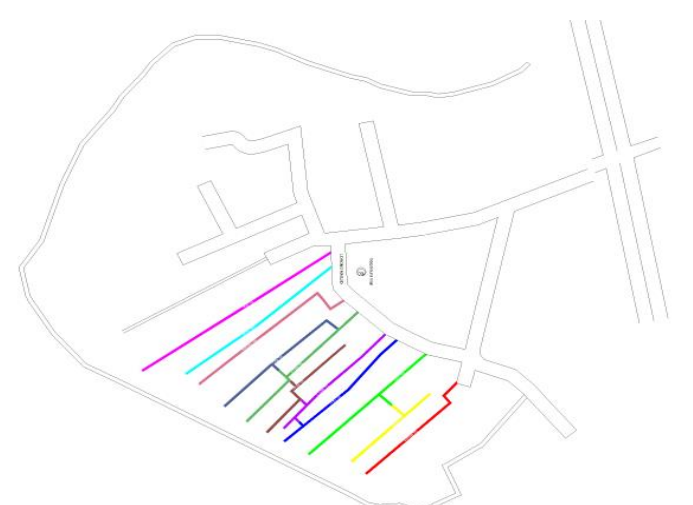

Gambar 1. Letak gang yang terdapat di Lorong Mesjid

Rumah bukan saja sebuah tempat untuk berteduh dari panas maupun hujan, namun juga sebuah tempat untuk membentuk karakter penghuninya sehingga dibutuhkan kondisi 
rumah yang layak. Keadaan perumahan di Lingkungan Lorong Mesjid dibuat dengan bahan seadanya yang menciptakan kesan kumuh pada bangunan rumah.

Kondisi fisik permukiman meliputi fasilitas atau infrastruktur dasar rumah tangga atau fasilitas umum, sedangkan kondisi sosial meliputi keadaan penghuni permukiman dilihat dari pendidikan serta tingkat pendapatan warganya (Gambar 2-5).

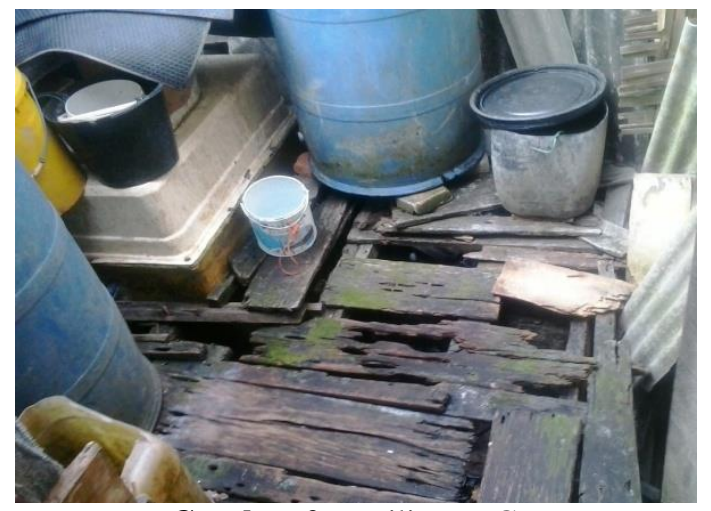

Gambar 2. Fasilitas MCK

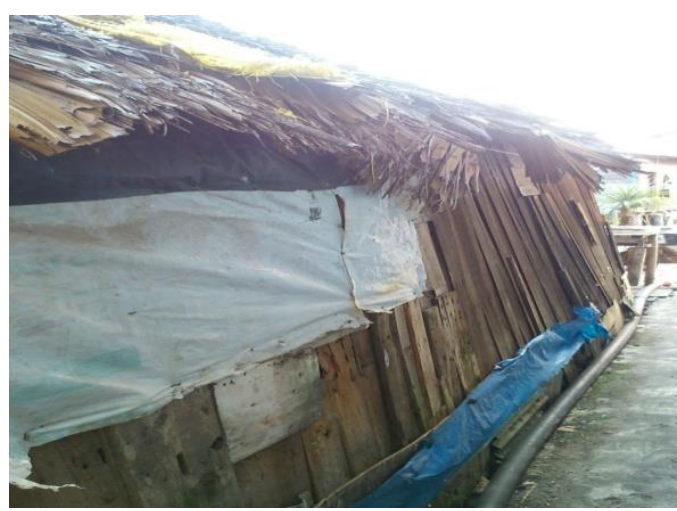

Gambar 3. Kondisi Rumah Penghuni

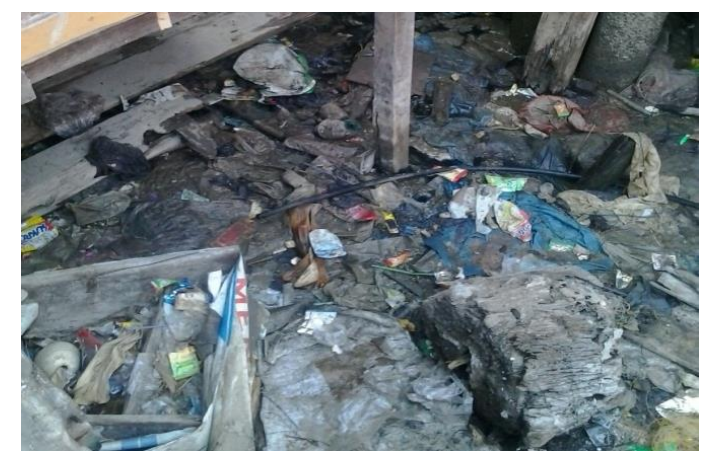

Gambar 4. Kondisi Lingkungan

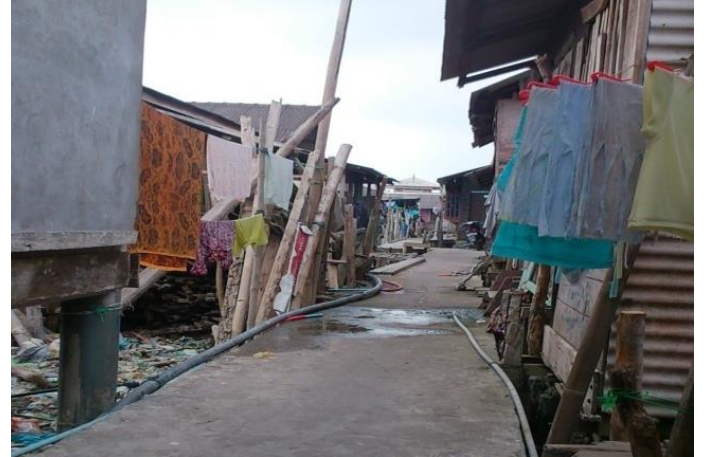

Gambar 5. Permukiman padat

Sampah menjadi masalah utama yang menciptakan kekumuhan di sebuah kawasan. Penumpukan sampah semakin memperkeruh rusaknya lingkungan fisik permukiman baik dari sisi kesehatan penghuninya maupun sisi kebersihan lingkungan.

Kepadatan lingkungan juga mendukung permukiman menjadi kumuh karena jarak satu rumah ke rumah lainnya belum sesuai dengan kriteria ideal jarak rumah.

Dalam menentukan faktor apa saja yang menyebabkan terjadinya permukiman kumuh, terlebih dahulu dilihat karakteristik permukiman kumuh yang mencakup karakteristik penghuni dan karakteristik tempat hunian seperti keadaan rumah dan sarana prasarana yang menunjang di permukiman tersebut.

Areal penelitian dilakukan pada lingkungan Lorong Mesjid yang memiliki 11 gang. Areal ini merupakan areal terkumuh di Kelurahan Bagan Deli. Faktor-faktor penyebab permukiman kumuh dapat digolongkan sebagai berikut:

\section{Faktor Fisik}

a. Keadaan Rumah

Lantai rumah penduduk di wilayah Kelurahan Bagan Deli terbuat dari kayu dengan kondisi yang sudah usang, kondisi dinding rumah penduduk sebagian besar terbuat dari papan yaitu $66 \%$, pondasi masih ada terbuat dari kayu sekitar $22 \%$, atap rumah terbuat dari seng, namun tanpa dilapisi plafon sehingga panas pada siang hari.

b. Jenis Rumah

Kondisi bangunan sebagian besar non permanen dengan luasan yang minimal dan tidak tertata serta tidak memenuhi syarat kesehatan. Bahan bangunan 
menggunakan bahan seadanya dan kurang layak.

c. Kepadatan Bangunan

Kepadatan bangunan tinggi dengan ratarata setiap gang dihuni oleh $10-25$ kepala rumah tangga dengan keseluruhan terdapat 199 kepala rumah tangga yang terdapat di Lorong Mesjid. Peningkatan jumlah penduduk mengakibatkan semakin meningkatnya kebutuhan akan tempat tinggal sehingga mengakibatkan kepadatan bangunan. Melihat kondisi lahan yang terbatas mengakibatkan tidak adanya jarak antar bangunan hunian sesuai dengan standart yang ditentukan sehingga kawasan ini menjadi kumuh karena padatnya rumah yang dibangun.

d. Jumlah Penghuni dalam satu rumah Jumlah penghuni dalam satu rumah juga ikut andil dalam membentuk kekumuhan suatu kawasan. Jumlah ideal dalam satu rumah adalah 5 orang, namun faktanya di Lingkugan Lorong Mesjid terdapat rata-rata 6-7 orang yang menempati 1 rumah. Jika jumlah penghuninya bertambah maka pemilik rumah menambahkan atau memperluas bangunan mereka tanpa menghiraukan aturan-aturan yang berlaku.

e. Sirkulasi udara dan pencahayaan di dalam rumah

Dengan melihat keadaan kepadatan bangunan yang terdiri dari 10-25 kepala rumah tangga di setiap gangnya, tentu keadaaan pencahayaan rumah menjadi kurang karena tertutupi bangunan rumah lainnya. Situasi sirkulasi udara juga tidak berbeda, akibat kepadatan bangunan penduduk, maka sirkulasi udara menjadi tidak maksimal karena ventilasi udara tidak banyak membantu udara bebas masuk keluar rumah.

\section{Faktor Ekonomi}

\section{a. Jenis Pekerjaan}

Mayoritas pekerjaan warga Kelurahan Bagan Deli Lorong Mesjid adalah sebagai nelayan yang bekerja tergantung pada keadaan cuaca dan musiman dalam melaut. Sedangkan para perempuan di Lingkungan ini mayoritas berprofesi sebagai ibu rumah tangga. Sehingga penghasilan suami sebagai pencari ikan menjadi sumber penghasilan utama bagi setiap rumah tangga di Lingkungan Lorong Mesjid ini.

b. Penghasilan

Karena sebagian besar penduduk bekerja sebagai nelayan sehingga hanya memiliki pendapatan tidak tetap sebesar Rp 20.000 s/d Rp 150.000 tergantung cuaca dan musim dalam melaut, bahkan tidak jarang para nelayan pulang dengan tangan kosong. Melihat dengan kondisi perekonomian penghuni yang relatif rendah tentu kemampuan penghuni permukiman ini dalam merealisasikan perbaikan lingkungan huniannya sangatlah tidak mungkin. Kebutuhan pemenuhan kelangsungan hidup, seperti sandang dan pangan menjadi prioritas utama penghuni dalam mengalokasikan pengeluaran mereka. Sehingga menurut mereka dengan kondisi kehidupan yang berada pada lingkungan yang kurang terawat dan kumuh sudah memberikan kenyamanan dan kepuasan bagi para penghuni untuk menempati lingkungan ini. Faktor penghasilan juga mengakibatkan kepemilikan lahan di Lingkungan Lorong Mesjid masih dengan sistem sewa yaitu sebesar $37 \%$. Dengan sistem sewa ini tentu akan semakim memberatkan penghuni karena harus menambah pengeluaran lebih untuk sewa bangunan. Hal ini juga memicu kebanyakan penghuninya tidak memperdulikan keadaan atau kondisi hunian yang mereka sewa. Sehingga jika terjadi kerusakan pada hunian tersebut, penghuninya tidak memperdulikannya karena merasa hal itu bukan tanggung jawab mereka. Tentu saja semakin lama kondisi hunian tersebut akan semakin buruk karena tidak dipelihara.

3. Faktor Persediaan Infrastruktur Lingkungan a. Air Bersih

Tidak terdapat fasilitas air bersih PDAM di Kelurahan Bagan Deli Lorong Mesjid sehingga seluruh warga diharuskan menggunakan air sumur bor, tetapi tidak semua warga Kelurahan Bagan Deli Lorong Mesjid memiliki sumur bor, oleh karena itu bagi warga yang tidak memiliki sumur bor, mereka harus membeli air dari salah satu warga yang mempunyai fasilitas sumur bor dengan harga Rp 6.000/jam. 
b. Fasilitas MCK

Kelurahan Bagan Deli Lorong Mesjid telah memberikan fasilitas MCK kepada setiap warga. Namun dalam kenyataannya banyak masyarakat yang tidak menggunakan fasilitas MCK tersebut dikarenakan tidak adanya perawatan pada fasilitas MCK tersebut. Sehingga masyarakat melakukan kegiatan MCK langsung pada air laut dan ada juga yang membangun fasilitas MCK sendiri dengan keadaan seadanya dan kurang layak.

c. Sistem Drainase

Rendahnya kualitas lingkungan permukiman terutama pada daerah seputar saluran pembuangan/drainase yang digunakan sebagai tempat pembuangan sampah yang mengakibatkan kondisi jalur drainase menjadi kotor dan tersumbat. Kondisi drainase pun tak luput dari sampahsampah yang berserakan, hal ini disebabkan karena tidak adanya tempat pembuangan sampah yang memadai di Kelurahan Bagan Deli. Saluran air drainase tersebut juga sudah terkontaminasi sampah sehingga membuat airnya menjadi hitam dan mengeluarkan bau yang tidak sedap pula.

d. Pembuangan Air Limbah

Fasilitas pembuangan air limbah belum sesuai dengan kriteria, rata-rata setiap rumah tangga belum memiliki sistem pembuangan limbah sehingga air limbah langsung dibuang ke laut yang mengakibatkan pencemaran air laut di sekitar permukiman tidak bisa dihindarkan.

e. Jalan Lingkungan dan Penerangan Jalan Pada kawasan Bagan Deli ini kisaran jalan lingkungan di masing-masing gangnya tidak sesuai dengan ketentuan jalan lingkungan yang diatur. Setiap jalan lingkungan memiliki lebar tidak lebih dari $1,5 \mathrm{~m}$, dan belum memiliki fasilitas penerangan jalan lingkungan, sehingga pada malam hari gang di Lingkungan Lorong Mesjid menjadi gelap dan hanya diterangi oleh lampulampu rumah warga. f. Sampah Lingkungan

Petugas kebersihan dari pemerintah pun dirasa kurang efisien dalam mengangkut sampah rumah tangga warga karena hanya dilakukan sekali seminggu saja. Hal ini mengakibatkan penumpukan sampah sisa-sisa rumah tangga warga yang mengeluarkan bau tidak sedap sehingga jalan satu-satunya yang dilakukan warga adalah langsung membuang sampah tersebut ke laut sekitar rumah mereka.

g. Intesitas Banjir

Lingkungan Lorong Mesjid merupakan daerah langganan banjir sekalipun dengan intensitas hujan yang rendah, akibat saluran drainase yang tidak berfungsi pada saat pasang yang dikarena kondisi perumahan yang berada di atas permukaan laut.

4. Faktor Sosial dan Budaya

a. Kesehatan

Akibat sampah yang menumpuk di sekitar Lingkungan Lorong Mesjid tentu akan menimbulkan banyak bibit penyakit, ditambah aroma tidak sedap yang ditimbulkan oleh sampah yang menumpuk mengakibatkan udara di sekitarnya menjadi tidak sehat.

b. Pendidikan

Melihat mayoritas pekerjaan para penghuni yang rata-rata bekerja sebagai nelayan dan ibu rumah tangga, tentu para penghuninya tidak memiliki pendidikan yang tinggi dikarenakan pekerjaan yang dilakukan adalah pekerjaan sektor informal yang tidak memiliki pendidikan khusus untuk dilakukan.

c. Kebiasaan Penghuni

Tidak adanya kesadaran dari masyarakat akan pentingnya hidup sehat dan nyaman menjadi salah satu faktor yang mengakibatkan kekumuhan di sekitar kawasan ini. Membuang limbah rumah tangga dengan sembarangan di sekitar rumah atau langsung ke laut menyebabkan pemandangan sekitar menjadi kumuh dan kotor dan bau yang tidak sedap yang pasti akan menambah kekumuhan ini. Selain kesadaran untuk tidak membuang sampah sembarangan, kesadaran akan memelihara fasilitas umum juga tidak dimiliki oleh masyarakat, seperti fasilitas drainase atau 
pembuangan yang turut menambah masalah kekumuhan di kawasan ini.

Setalah mengetahui faktor-faktor penyebab kemiskinan, tahap selanjutnya adalah membuat rencana penanggulangan kekumuhan.

1. Revitalisasi Bangunan Permukiman

Peningkatan jumlah penduduk bukan hanya terjadi akibat dari meningkatnya angka kelahiran, namun juga terjadi akibat dari urbanisasi (Ballesteros, 2010). Hal ini dilakukan oleh penduduk, banyak diantara penghuni Lingkugan Lorong Mesjid mengajak sanak keluarganya yang lain untuk tinggal di kawasan itu dengan harapan untuk mencari kehidupan yang lebih layak dari daerah asalnya atau sekedar membantu pekerjaannya sebagai nelayan. Kepadatan ini turut mendukung permukiman yang semakin padat. Untuk mengatasi kepadatan ini, relokasi bukan merupakan solusi tepat, namun pembangunan rumah susun bagi penghuninya dapat menjadi solusi tepat karena desain rumah susun yang bertingkat akan bisa menghemat lahan yang ada.

Selain revitalisasi bangunan, status kepemilikan tanah atas bangunan rumah susun yang kan dibangun juga harus diperjelas. Sebanyak $37 \%$ lahan di Lingkungan Lorong Mesjid berstatus sewa, baik itu tanahnya ataupun bangunannya. Artinya penduduk dengan rumah berstatus sewa memiliki beban lebih berat dikarenakan harus membayar uang sewa lagi setiap tahunnya. Untuk itu diperlukan solusi untuk mengatasi masalah isu kepemilikan tanah ini yang memberatkan masyarakat (Pelikka et al, 2004). Solusi terbaik yang dapat diberikan adalah menjadikan lahan sewa tersebut menjadi lahan milik pemerintah dimana pemerintah membeli lahan tersebut dan di atasnya dibangun rusun denga biaya sewa yang dipastikan tidak akan memberatkan para penghuninya.

2. Pemberdayaan Ekonomi dan Sumber Daya Masyarakat

Kondisi permukiman kumuh juga tidak lepas dari keadaan ekonomi para penghuninya. Penghasilan nelayan yang tidak tetap diperburuk oleh tidak adanya penghasilan para istri nelayan yang ratarata berprofesi sebagai ibu rumah tangga sehingga sumber pendapatan utama setiap rumah tangga di kawasan itu adalah dari hasil laut. Kondisi ini seharusnya dapat diatasi dengan program mikro kredit (Siddique at al, 2002) untuk meningkatkan pendapatan rumah tangga para penghuninya. Dana dari program mikro kredit ini nantinya digunakan oleh para istri untuk membuat produk olahan baru dari hasil laut sehingga menambah nilai guna produknya, misalnya dengan membuat olahan bakso dari ikan, membuat olahan kerupuk ikan yang nantinya hasilnya akan dijual ke publik.

3. Pemberdayaan Edukasi Lingkungan

Tingkat kesadaran para penghuni permukiman kumuh tergolong sangat rendah. Memiliki rumah dengan lingkungan yang sehat dan bersih bukan merupakan prioritas bagi mereka. Lingkungan kumuh yang tidak sehat akan berdampak pada kesehatan fisik dan mental para penghuninya (Ballesteros, 2010). Kepadatan permukiman sudah tentu akan menimbulkan masalah lingkungan, ditambah dengan tidak adanya pengetahuan dasar para penghuni akan hidup sehat tentu akan memperburuk kondisi permukiman. Untuk itu diperlukan edukasi atau pendidikan dasar mengenai pentingnya hidup di lingkungan yang sehat dan bersih. Edukasi ini diharapkan akan menambah pengetahuan penghuni dan meningkatkan kesadaran mereka untuk menjaga lingkungan sekitar rumah maupun lingkugan di dalam rumah itu sendiri.

4. Revitalisasi \& Pengadaan Infrastruktur Hal ini mencakup sarana dan prasarana dasar yang dimiliki permukiman. Pelayanan atau infrastruktur dasar mencakup jalan lingkungan, drainase air hujan, fasilitas MCK, fasilitas air bersih, dan sistem pembuangan limbah. Secara fisik program penanggulangan yang terbaik adalah melakukan revitalisasi terhadap sarana infrastruktur yang ada, seperti Program Peningkatan Kesejahteraan \& perbaikan infrastrukutur (Dasgupta \& Somik, 2006) yang dapat meningkatkan kualitas infrastruktur dasar pemukiman kumuh. 


\section{KESIMPULAN}

Dari hasil penelitian diperoleh 4 faktor yang menyebabkan kekumuhan di permukiman ini, yaitu (1) Faktor Fisik, meliputi kondisi eksisiting rumah, jenis rumah, kepadatan bangunan, jumlah penghuni yang menempati 1 rumah, sirkulasi udara dan pencahayaan rumah; (2) Faktor Ekonomi, meliputi jenis pekerjaan penghuni dan penghasilan; (3) Faktor persedian Infrastruktur Lingkungan, meliputi air bersih, fasilitas MCK, sistem drainase, pembuangan air limbah, jalan lingkungan dan penerangan jalan, sampah lingkungan, dan intensitas banjir; (4) Kondisi sosial dan budaya yang meliputi kesehatan, pendidikan dan kebiasaan penghuni.

Setelah mengetahui faktor-faktor apa saja yang mengakibatkan kekumuhan di Lingkungan Lorong Mesjid, maka perlu dilakukan program penanggulangan kekumuhan pada kawasan ini yang meliputi (1) Revitalisasi Bangunan Permukiman; (2) Pemberdayaan Ekonomi dan Sumber Daya Masyarakat;

Pemberdayaan Edukasi Lingkungan;

Revitalisasi \& Pengadaan Infrastruktur.

Revitalisasi atau pembangunan kembali merupakan solusi utama dalam mengatasi kekumuhan dari segi fisik, namun hal ini bukan merupakan satu-satunya solusi yang harus dilakukan. Perbaikan secara sosial ekonomi juga sangat dibutuhkan dalam mengatasi kekumuhan sebuah kawasan karena program untuk meningkatkan pendapatan para penghuninya juga merupakan solusi jangka panjang yang dapat dilakukan untuk meningkatkan kualitas hidup para penghuninya.

\section{Daftar Pustaka}

Bagheri, M. (2012) The challenge of slums: socio-economic disparities. International Journal of Social Science and Humanity, 2, 412-413.

Ballesteros, M.M. (2010) Linking Poverty and the Environment: Evidence from Slums in Philippine Cities. Discussion Paper Series No. 2010-33.

Bandyopadhyay, A. dan Agrawal, V. (2013) Slums In India: From Past To Present. International Refereed Journal of
Engineering and Science (IRJES),2 (4), 55-59.

Bolay, J.C. (2006) Slums and Urban Development: Questions onSociety and Globalisation. The European Journal of Development Research, 18 (2), 284298.

Çiçeklioğlu, M., Ergin, I., Demirelöz, M., Ceber, E., dan Nazl1, A. (2012) Sociodemographic aspects of consanguineous marriage in an urban slum of a metropolitan area in Izmir, Turkey, Annals of Human Biology, 40(2), 39-145.

Dagdeviren, H dan Robertson S.A. (2011) Access to Water in the Slums of SubSaharan Africa Development Policy Review, 29 (4), 485-505.

Dasgupta, B., Somik V dan Lall. A. (2006) Assessing Benefits Of Slum Upgrading Programs In Second-Best Settings. World Bank Policy Research Working Paper 3993.

Desai, V dan Alex Loftus. (2012) Speculating on Slums: Infrastructural Fixes in Informal.

Goswami, S dan Manna, S. (2013) Urban Poor Living in Slums: A Case Study of Raipur City in India. Global Journal of HUMAN SOCIAL SCIENCE Sociology \& Culture, 13 (4) Version 1.0.

Gulyani, S., Ellen, M.B dan Debabrata, T. (2012) Land Economics Housing in the Global South, Antipode, 45 (4), 789 808.

Idowu, O.O. (2013) Challenges of Urbanization and Urban Growth in Nigeria. American Journal of Sustainable Cities and Society. 2 (1), 79-95.

Marx, B., Stoker,T., dan Suri, T. (2013) The Economics of Slums in the Developing World. Journal of Economic Perspectives. 27(4), 187-210. 
Pelikka, P., J. Ylhäisi dan B. Clark (eds.) Taita Hills and Kenya, (2004) Seminar, reports and journal of a field excursion to Kenya. Expedition reports of the Department of Geography, University of Helsinki 40, 64-78.

Peraturan Menteri Pekerjaan Umum, Undangundang No. 4 Tahun 1992, tentang Perumahan dan Permukiman.

Pryer, J.A dan Rogers, S. (2006) Epidemiology of undernutrition in adults in Dhakaslum households, Bangladesh, European Journal of Clinical Nutrition, 60, 815822.

Roy, D., Michael, H.L., Bharath, P., Karin, P dan M.A. Peter Sloot. (2014) The emergence of slums: A contemporary view on simulation Models. Environmental Modelling \& Software 59, 76-90.

Sakdapolrak, P.,Thomas, S dan Christina, E. (2013) Burden of direct and indirect costs of illness: Empirical findings fromslum settlements in Chennai, South India Progress in Development Studies 13 (2), 135-151.

Siddique, Q.I., Alam, A.B.M., Rahman, M., Rahman, A dan Jahan, Hasin. (2002) Slum Improvement Project in Dhaka Metropolitan City. Asian Perspective, Habitat Exchange, Toronto University, Canada.

Ucha, C. (2010) Poverty in Nigeria: Some Dimensions and Contributing Factors. Global Majority E-Journal, 1 (1), 4656. 